\title{
A leitura de jornal e a exclusão de idosos
}

\section{The newspaper reading and the elderly's social exclusion}

\author{
La lecture de journal et l'exclusion sociale de \\ personnes âgées
}

\author{
Adriana Pastorello Buim ARENA
}

\section{RESUMO}

Este artigo tem como objetivo verificar se idosos, moradores em um asilo, da cidade de Marília, sentem necessidade da leitura em seu cotidiano. Participaram da pesquisa por amostragem, sete idosos, com idades variando de 74 a 99 anos. Os participantes foram divididos em dois grupos: grupo leitor e o grupo não-leitor. Responderam à entrevista semi-estruturada que resultou na possibilidade de discutir o conteúdo da educação de idosos que se encontram em asilos, suas necessidades e sua reintegração social.

Palavras-chave: idosos, leitura de jornal, exclusão social, Marília.

\section{ABSTRACT}

This article has as objective to check if elderly, residents of a home for old people in the town of Marília, feel the necessity of reading in their daily life. Seven old people participated of the sampling, between 74 to 99 years old. The participants were divided in two groups: reader group and non-reader group. They answered the semi-structured interview which resulted in the possibility of discussing the contents of the elderly's education that are in homes for old people, their needs and social reintegration.

Index terms: elderly, newspaper reading, social exclusion, Marilia.

\section{RÉSUMÉ}

Cet article a pour objectif vérifier si des personnes âgées, habitants dans une maison de retraite (résidence), de la ville de Marília, éprouvent la nécessité de lire dans leur vie quotidienne. Sept personnes âgées, dont l'âge variait entre 74 et 99 ans, ont participé à la recherche par échantillonnage. Les participants ont été séparés en deux groupes: groupe de lecteur et 
groupe de non-lecteur. Ils ont répondu à une interview semi-structurée qui a rendu possible la discussion sur le contenu de l'éducation des personnes âgées qui se trouvent dans des maisons de retraite (résidence), de leurs nécessités et de leur réintégration sociale. Marília.

Mots clés: personnes âgées, lecture de journal, exclusion sociale,

\section{Introdução}

A Constituição Federal de 1988 estabelece no artigo 205 que "a educação é direito de todos e dever do estado e da família...” e ainda, no artigo 208 inciso I, que o dever do Estado com a educação será efetivado mediante a garantia de "ensino fundamental obrigatório e gratuito, inclusive sua oferta gratuita para todos os que a ele não tiveram acesso na idade própria”. Apoiado na Constituição, o Conselho Estadual de Educação na Deliberação CEE nº. 09/2000, estabelece diretrizes para a implementação, no sistema de ensino do Estado de São Paulo, dos cursos de educação de jovens e adultos de níveis fundamental e médio, instalados ou autorizados pelo Poder Público.

O artigo $2^{\circ}$ da lei em questão delibera: "Os cursos de educação de jovens e adultos destinam-se àqueles que não tiveram acesso ou continuidade de estudos no ensino fundamental e médio, na idade própria”. Ao explicitar que têm direito a educação "aqueles que não tiveram acesso ou continuidade de estudos no ensino fundamental e médio, na idade própria" a lei inclui milhões de analfabetos, não importando a idade, na tentativa de corrigir um erro cometido desde a colonização.

Segundo dados do Instituto Brasileiro de Geografia e Estatística IBGE, o índice de analfabetismo no Brasil caiu de 17,2\% em 1992 para 13,3\% em 1999, conforme dados do Censo 2000 sobre educação, divulgado 
dia 2 de dezembro de 2003 que aponta a existência de 24 milhões de analfabetos no país.

Apesar desta queda, o índice brasileiro ainda pode ser considerado muito alto. Ao constatar que 24 milhões de brasileiros não possuem uma das condições básicas para serem cidadãos participantes de uma sociedade letrada, podemos concluir que sofreram uma forma de exclusão social, a exclusão escolar. Embora o governo reconheça essa situação, a Educação de Jovens e Adultos (EJA) tem grandes problemas a serem administrados, tanto de ordem econômica como também pedagógica.

O Governo Federal não assume financeiramente toda a responsabilidade da EJA. Conta com a ajuda de instituições que promovem, em parceria com o Estado, a instalação de serviços para oferecer a todos que não tiveram acesso à educação, a possibilidade de integrar-se na comunidade letrada deste país. Por outro lado, também há a dificuldade pedagógica da formação do currículo para as classes de EJA. Em cada sala formada, há pessoas que buscam interesses diferentes, como também têm condições físicas diferentes. Uma sala de alunos de 20 a 50 anos tem um perfil diferente de uma sala com alunos de 75 a 85 anos. É preciso considerar o envelhecimento e buscar descobrir como idoso pode aprender, levando em consideração que, com o processo de envelhecimento, ocorre um declínio das funções cognitivas.

Segundo Paiva (2001), os adultos devem aprender a ler e a escrever no mundo de hoje para serem membros efetivos da sociedade. Ensinar alguém que já passou metade de sua vida sem o conhecimento da escrita é devolver the o direito que lhe foi negado durante metade de sua vida, dificultando sua sobrevivência e submetendo-os a condições inferiores diante de seus pares. 
Neste artigo, tratamos de pesquisa que teve como objetivo o de levantar dados sobre as necessidades que idosos entre 74 a 99 anos têm em relação à leitura. $\mathrm{O}$ mesmo pretende discutir o processo de integração do idoso no mundo letrado, levando em conta o processo de envelhecimento, as possibilidades e limites da velhice e a diversidade cultural.

\section{Sujeitos da pesquisa}

O relato que será apresentado foi dividido em dois momentos diferentes conforme os fatos ocorridos no contato com as idosas, em um asilo, em Marília - SP, em 2006. No primeiro momento, houve uma atividade de leitura de jornal. No segundo momento, uma entrevista semiestruturada sobre o interesse de cada uma delas pela leitura.

Não foi possível considerar o grupo total de moradores do asilo devido às condições de saúde de muitos deles. Por isso a amostra da pesquisa é um subconjunto do total de moradores, todas senhoras. Para a definição do grupo de sujeitos, foi considerada a saúde física das idosas e a disposição para participar da entrevista. Portanto, a pesquisa não tem como finalidade generalizar conclusões para toda a população de moradores da instituição em questão. A natureza desta pesquisa é qualitativa e não quantitativa; não prioriza a generalização dos resultados obtidos pela amostra, mas apenas a descrição, compreensão e interpretação dos fenômenos observados com um grupo específico de senhoras.

No primeiro momento, a pesquisa se desenvolveu apenas com duas idosas que sabiam ler. Já no segundo momento, foram entrevistadas duas senhoras que sabiam ler e cinco que não sabiam ler, num total de sete entrevistadas. O critério de escolha para a seleção dos sujeitos foi o contato que já havia entre sujeitos e pesquisadora há algum tempo em atividades 
semanais de visitas. As idosas que não conseguiam sair da cama foram entrevistadas em seu próprio quarto. As outras, no jardim do asilo.

As entrevistas semi-estruturadas foram registradas pela pesquisadora durante um encontro de três horas. Este instrumento foi uma forma de confrontar os dados registrados no primeiro momento da pesquisa. A escolha por entrevista semi-estruturada deveu-se ao fato de possibilitar um roteiro preliminar e também a liberdade de acrescentar novas perguntas ao roteiro, com o objetivo de clarificar pontos importantes para a pesquisa.

\section{Primeiro momento: a leitura do jornal impresso}

Privilegia-se muito a escola como o lugar indicado para aprendizagem da leitura e da escrita, mas se esquece de que a leitura e a escrita do mundo real vão além da sala de aula. Os textos produzidos para a alfabetização de alunos em idade escolar adequada é normalmente um material inadequado, porque é produzido fora de um contexto social. Para Paiva (2001), a escola, ao receber os alunos, toma como verdade que nada sabem quando chegam aos bancos escolares. Isso parece ser contraditório quando se refere a sujeitos que estão inseridos em uma sociedade que se organiza com base e em torno da língua escrita. Os adultos conseguem viver em um mundo letrado realizando diferentes formas de leitura de mundo apenas com os recursos que possuem, pois, em determinadas situações, o sujeito é obrigado a elaborar saídas ou táticas, nada convencionais, para seu convívio social. Segundo a autora, os educadores devem aproveitar o conhecimento prévio dos adultos para melhorar seu rendimento em sala de aula. Nenhum adulto se interessa em saber que " $A$ pata nada", pois não está em busca de textos produzidos artificialmente para aprender o código linguístico, mas em textos que encontram na sociedade e a falta dessa leitura dificulta sua vida. Segundo Paiva (2001, p.11), "a leitura e a 
condição do ser leitor na sociedade, nos modos como vem sendo exigida a sua formação, carecem de muito mais que o mero aprendizado do código escrito".

Motivada com a possibilidade de levar atividades de leitura que realmente fossem significativas para que as idosas desenvolvessem atividades cognitivas e assim preservassem as habilidades mentais, disponibilizei jornais de grande circulação e de pequena circulação para iniciar um trabalho de leitura julgando que seria um material de grande aceitação.

Propus desenvolver um trabalho de leitura do jornal impresso, reconhecendo sua grande estrutura.

Logo no início, todas disseram que era muito bom ler jornal, e que gostariam de participar da atividade. No entanto, nenhuma delas participou de fato. Uma senhora olhava as fotos e se fixou em uma, a de um velhinho. Acariciava a foto e lia algumas palavras da legenda. Como pesquisadora, insistia que lessem o que estava escrito para que depois conversássemos sobre o assunto lido. Fazia perguntas sobre manchetes, fotos para levantar dúvidas ou curiosidade sobre os mais variados assuntos abordados pelo jornal. Ignoravam minhas propostas. Algumas idosas liam em voz alta ou sussurrando, demonstrando saber decodificar o código linguístico, mas no momento de conversar sobre o assunto fugiam da conversa perguntando sobre outros temas relativos a minha vida pessoal, se era casada, se tinha filhos, se já tive dor na coluna, ou seja, assuntos voltados para os problemas que elas próprias viviam. Quando insistia e eu voltava a perguntar sobre o assunto lido elas apenas repetiam algumas palavras lidas sem realmente encontrar sentido. Aos poucos, fui perguntando sobre eventos que estavam acontecendo no país e na cidade e ninguém estava informado sobre acontecimentos sociais. Eles estavam alheios ao mundo vivendo um mundo paralelo, o mundo do abrigo em que vivem. 
A boa intenção de levar a leitura de jornais para os velhinhos fracassou. É preciso considerar não só o conhecimento do código linguístico, mas também os conhecimentos prévios são recursos para que a leitura com compreensão aconteça. Faltava interação com o mundo social para entender e querer saber sobre ele. Surgiu-me a pergunta: qual é o material de leitura que os idosos têm interesse?

\section{Segundo momento: o que desejam aprender os idosos}

Devido ao baixo interesse demonstrado pelas idosas na atividade com o jornal, optei por entrevistar aquelas senhoras e outras que não sabiam ler sobre suas necessidades e perspectivas.

As entrevistas seguiam o roteiro abaixo:

\begin{tabular}{|l|l|}
\hline Idosas que sabiam ler & Idosas que não sabiam ler \\
\hline Você sabe ler? & Você sabe ler? \\
Se sim, & Se não, \\
Quando aprendeu? & Gostaria de aprender a ler? \\
O que mais gosta de ler? & Que tipo de material \\
& gostaria de ler? \\
\hline
\end{tabular}

Tabela 1 - Roteiro de entrevistas para idosas.

Sabe-se que para alfabetizar é preciso dar sentido ao código em contextos sociais. A leitura não pode ser entendida como decifração do código linguístico, a compreensão é a base, é processo é intenção que são constituintes da ação de ler, e criadores produtores de um objeto imaterial, existente nessa relação efêmera entre o leitor e o texto a que se dá o nome de leitura. A leitura assim compreendida, não estaria fora do sujeito, materializada nos livros ou em qualquer outro material impresso: está na relação do homem com o mundo do impresso. Virtual e imaterial é criada pela intenção que tem o leitor por compreender e se transforma ao 
transformar o próprio modo de pensar e de organizar o conhecimento desse leitor. O processo de ler não atingiria o seu ponto bom quando o leitor atribui, no limite de seu conhecimento e de suas capacidades, sentidos ao texto, mas quando transforma o pensamento e o modo de pensar do leitor, porque, se assim fosse, de pouco serviria aprender e saber ler (ARENA, 2006, p.415).

Na relação ensino e aprendizagem, tanto em salas de idade regular como em salas de EJA, os alunos não falam a mesma linguagem dos professores, esses também não têm os mesmos conhecimentos prévios, porque, se assim fosse, poder-se-ia simplesmente transferir as informações de um para outro, ou melhor, de professor para aluno. Investigar sobre o conhecimento informal que os adultos têm e identificar seus interesses é fator essencial para conduzir o ensino da leitura e da escrita. Ensinar com materiais que circulam no cotidiano do aluno como folhetos de supermercado, tabelas de preços de materiais de construção, revistas de corte e costura que ensinam a traçar molde, ou até mesmo livros de receitas de culinária, podem ser textos propulsores do desenvolvimento da leitura, porque correspondem às necessidades e dúvidas de cada adulto em relação ao mercado de trabalho em que estão inseridos. Com eles aparecerão determinadas situações que possibilitarão aos alunos atribuir sentido ao processo de ensino e aos atos de leitura, porque correspondem a sua realidade. E para idosos que já não ocupam o mercado de trabalho, não andam sozinhos pelas ruas, não frequentam casas de parentes, não convivem de maneira alguma com o mundo fora dos muros do abrigo, que lhes ensinar? Como ressignificar o código linguístico?

Com essa preocupação, relatarei neste momento o resultado da entrevista com as idosas que não sabiam ler, registrando suas explicações e desejos. Os nomes que aparecem não correspondem aos nomes reais, são 
ficcionais, pois não foi autorizada pela instituição sua divulgação. Quanto à idade também não foi possível confirmá-las, pois não tive acesso aos documentos para comprovação.

\begin{tabular}{|c|c|}
\hline Nome e idade & Dados da entrevista \\
\hline Ana & $\begin{array}{l}\text { Não respondeu a nenhuma pergunta. Disse que tinha } \\
\text { vista cansada, não enxergava bem e decidiu dar uma } \\
\text { volta pelo jardim abandonando a conversa. Sentia-se } \\
\text { constrangida em responder que não sabia ler. }\end{array}$ \\
\hline Rosa & $\begin{array}{l}\text { Não sabe ler, mas respondeu que folheia revistas para } \\
\text { passar o tempo. Declarou que não consegue mais } \\
\text { aprender, porque não consegue ficar atenta às letras, mas } \\
\text { disse que tem muita vontade de saber ler, porque se } \\
\text { soubesse leria "para passar o tempo". }\end{array}$ \\
\hline Sebastiana 74 & $\begin{array}{l}\text { Nunca aprendeu a ler, sente-se muito solitária e gostaria } \\
\text { de aprender a ler "para passar o tempo mais rápido". } \\
\text { Gostaria de ler romances, "só coisas bem bonitas". }\end{array}$ \\
\hline Ermínia & $\begin{array}{l}\text { Não consegue ler, mas frequentou a escola. Saiu antes } \\
\text { que aprendesse. Gostaria de ler qualquer coisa, mas } \\
\text { agora não tem disposição porque sua coluna dói muito. }\end{array}$ \\
\hline Ernestina & $\begin{array}{l}\text { Quer muito aprender a ler, mas não consegue. Ganhou } \\
\text { um livro de literatura infantil "A galinha dos ovos de } \\
\text { ouro", mas a pessoa leu apenas uma só vez para ela e } \\
\text { isso não foi suficiente para que aprendesse. Ela não sabe } \\
\text { o que gostaria de ler. Disse que primeiro tem que ler } \\
\text { para saber do que vai gostar. }\end{array}$ \\
\hline
\end{tabular}

Tabela 2- Relato da entrevista com cinco idosas que não sabiam ler

Diante das respostas obtidas pelas entrevistas, é possível compreender como o idoso perde com a falta de escolaridade no tempo em 
que tinha condições físicas mais adequadas para aprender. Essa é uma perda que não se pode reverter, mas apenas compensar com algumas atividades que reintegrem o idoso ao convívio social para que ele se sinta aceito na comunidade em que está. É bastante esclarecedor na fala de duas senhoras, que a leitura ajudaria a "passar o tempo". Não podem mais ajudar em trabalhos domésticos simples e têm muita dificuldade em outros tipos de trabalhos manuais como pintura, crochê e todo o tipo de artesanato. Ler seria uma atividade mental que preencheria o tempo, impediria lembranças e pensamentos ruins e desenvolveria a atividade cognitiva necessária para evitar um envelhecimento precoce do cérebro.

O resultado da entrevista realizada com dona Ernestina traz outro fato curioso que nos faz refletir. Muitas pessoas na tentativa de recuperar esses idosos e trazê-los para o mundo letrado oferecem materiais que não correspondem a sua idade. No entanto, o comportamento do idoso, devido à ausência das atividades sociais como trabalho e convivência com os familiares, retornam a comportamentos infantis, como por exemplo, brincar de bonecas, pintar livros infantis, ouvir histórias de fadas, jogar memória, dramatizar pequenas historinhas.

Estas são atividades comuns no cotidiano de um asilo. Para idosos com o perfil destes entrevistados, essas atividades acima citadas seriam muito bem aceitas por eles, mas não poderiam ser trabalhadas com os jovens e adultos que a EJA envolve. Observamos que a EJA não pode cumprir um único currículo. O que devolver para esses idosos que perderam seu direto de cidadão? Abandoná-los não seria justo. Reintegrá-los totalmente seria utópico, mas seria possível oferecer condições de melhorar sua auto-estima, e ajudar a ter um envelhecimento com melhores condições. 
A tabela abaixo registra o relato de duas idosas que sabem ler.

\begin{tabular}{|l|l|}
\hline Nome e idade & Dados da entrevista \\
\hline Maria 87 & $\begin{array}{l}\text { Sabe ler, mas não consegue se lembrar do que lê, } \\
\text { porque tem defasagem de memória. Relata ler todos } \\
\text { os dias, porque tinha esse hábito antes de ficar } \\
\text { esquecida. Usava livros de biblioteca e de amigos. } \\
\text { Hoje gosta de ler qualquer coisa, porque não se } \\
\text { importa com o conteúdo do texto, mas com o ato de } \\
\text { decifrar. }\end{array}$ \\
\hline Célia & $\begin{array}{l}\text { Sabe ler. Faz leituras diárias. Gosta de todos os tipos } \\
\text { de texto que aparecem no asilo: revistas, romance, } \\
\text { histórias de Cristo. Fez a seguinte declaração "tenho } \\
\text { dó delas que não conseguem ler, às vezes eu conto } \\
\text { para elas alguma história que li e que gostei." }\end{array}$ \\
\hline
\end{tabular}

Tabela 3 - Relato da entrevista com duas idosas que sabem ler.

É possível observar pelo relato, que o fato dessas duas senhoras terem tido o contato com a leitura antes do envelhecimento as ajudou a ter uma maior qualidade de vida, mesmo que isso signifique atenuar a solidão, sentimento apresentado por todas. O tempo passa rápido para quem está envolvido com uma série de responsabilidades, mas para moradores de um abrigo que não têm mais as condições físicas normais, o tempo demora a passar. Marcam o tempo pelo horário das refeições do dia. A leitura é uma companhia. Estas duas senhoras conseguem driblar o tempo e a solidão com materiais de leitura. A primeira, embora tenha o problema de esquecimento, ocupa sua mente com leituras, mesmo que depois não se lembre mais do assunto lido. Decifrar para ela é reconhecer que não perdeu totalmente a capacidade de sua memória. Incansavelmente lê aquilo de que não consegue se lembrar e sobre o que não consegue nem mesmo comentar. Mas, a outra, 
dona Célia, faz de suas leituras motivo de conversas com outras moradoras do asilo. A leitura proporciona um contato com o outro e a fuga da solidão.

Do que os idosos necessitam de acordo com essa amostragem? De pessoas que os ouçam e proporcionem atividades possíveis de serem concretizadas de acordo com as possibilidades físicas de cada um, como também de seus interesses.

\section{Da necessidade de um currículo específico}

A Resolução SE no 1, de 12 de janeiro de 2001, dispõe sobre a organização curricular dos cursos de Educação de Jovens e Adultos da rede estadual de ensino. $\mathrm{O}$ Artigo $2^{\circ}$ delibera:

A organização curricular dos cursos de educação de jovens e adultos, será composta:

I - por todas as disciplinas que compõem a Base Nacional Comum, conforme distribuição contida nas matrizes curriculares das Resoluções SE no 4/98 para o ensino fundamental e 7/98 para o ensino médio.

Embora saibamos que a lei é flexível e possibilita o ajuste da grade curricular dependendo das características particulares de cada classe, existe por parte da legislação a sugestão de um currículo já preparado para outra realidade bem adversa. Adotar um currículo para a terceira idade implica a adoção de uma série de critérios de natureza biológica, psicológica e sociocultural.

As evidências que podemos mencionar diante dos dados coletados explicam e apontam que a atividade de leitura para o idoso é um meio de estabelecer relações com outros sujeitos que vivem fora do abrigo, mas que trazem informações do mundo que os idosos não podem mais participar por diferentes motivos. Percebemos que o idoso quer e precisa desempenhar 
uma série de atividades, como exercícios para ajudar a melhorar a memória, relacionamentos com outras pessoas que não sejam somente os moradores do asilo, aprender pequenas coreografias como quadrilhas, atividades estas que podem ajudar a melhorar a sua vida.

Os idosos podem aprender a compensar algumas perdas decorrentes do envelhecimento por meio de estratégias. No caso de problemas de memória, os déficits podem ser compensados por meio de leituras de materiais que interessem a cada um em particular, como vimos pelas entrevistas, desde as histórias infantis, até as leituras de histórias sobre o Cristo. Não importa o que lêem, é preciso ler para compensar o estado de envelhecimento. Segundo Barbosa (Prelo, 2009, p.24), a proposta metodológica de ensino para os idosos merece mais atenção:

O projeto, as sequências didáticas e os gêneros textuais escolhidos seriam orientados pelo professor de acordo com as necessidades, interesses e desejos de cada aluno. Isso quer dizer que o atendimento não seria individualizado, tendo como base um trabalho comum a todos, mas personalizados, próprio para cada um, conforme suas necessidades e interesses, mas convergindo para a construção coletiva do trabalho de construção, organização e sistematização do conhecimento conquistado ao longo da vida.

Os dados aqui apresentados demonstram que o ensino proposto pela organização curricular dos cursos de Educação de Jovens e Adultos nem sempre será eficiente para o grupo específico de idosos. É importante reconhecer, com a ajuda dos idosos presentes em salas de aula de EJA, o que e como podem e querem aprender, quais as possibilidades físicas que cada um em especial tem como fonte geradora de aprendizagem e de desenvolvimento cognitivo. 
Uma série de fatores pode ajudar a promover o bem-estar e a qualidade de vida na terceira idade, como saúde física e mental, satisfação, competência social, produtividade, atividade, status social, continuidade de papéis sociais. Os profissionais da EJA levam para seus alunos adultos e idosos muito mais que um conteúdo didático a ser ensinado, porque a necessidade de ser querido e aceito socialmente na comunidade leitora é o que mais desejam.

\section{Conclusão}

Diante do quadro apresentado, podemos tirar duas conclusões. A primeira, é que a Educação de Jovens e Adultos no país é a demonstração real das falhas no cumprimento da lei. É preciso lutar para que um dia a EJA não faça parte da legislação educacional, porque todos receberão a educação no período correto.

A segunda, é que a Educação de Jovens e Adultos deve considerar outro sujeito que a palavra adulto quer envolver mas não consegue, o idoso. Este sujeito necessita de um novo currículo, diferente dos adultos e jovens que estão inseridos no mundo e no mercado de trabalho. É um grupo particular que merece atenção especial, porque estes cidadãos foram excluídos de seus direitos e resta, a eles, pouco tempo para retomar sua dignidade.

\section{Referências bibliográficas}

ARENA, D. B. (2006). Considerações sobre o estatuto do leitor crítico. In:

BARBOSA, R. L. (2009) L.Alfabetização do aluno-idoso: um desafio emergente. (No prelo)

BRASIL. Constituição da República Federativa do Brasil - Promulgada em 5 de outubro de 1988. 
SÃO PAULO. Deliberação CEE No . 09/2000 - Estabelece diretrizes para a implementação, no sistema de ensino do Estado de São Paulo, dos cursos de educação de jovens e adultos de níveis fundamental e médio, instalados ou autorizados pelo Poder Público.

IBGE. Situação educacional do Brasil ainda é "perversa". Disponível em: < http://www.mst.org.br/setores/educacao/educa5.htm>. Acessado em: 06 ago. 2006.

PAIVA, J. Novos significados para as aprendizagens da leitura na educação de jovens e adultos. In: Alfabetização e Cidadania. Revista de Educação de Jovens e Adultos. N. 12 - julho, 2001.

SÃO PAULO. Resolução SE Nº 1, de 12 de Janeiro de 2001 - Dispõe sobre a organização curricular dos cursos de Educação de Jovens e Adultos da rede estadual de ensino e dá providências correlatas

\section{Autora:}

Adriana Pastorello Buim Arena

Professor Adjunto I - Universidade Federal de Uberlândia

Faculdade de Educação - Faced

Grupo de pesquisa: Processos de leitura e de eserita: apropriação e objetivação.

Contato: adriana@faced.ufu.br

\section{Como citar este artigo:}

ARENA, Adriana Pastorello Buim. A leitura de jornal e a exclusão de idosos. Revista ACOALFAplp: Acolhendo a Alfabetização nos Países de Língua portuguesa, São Paulo, ano 5, n. 9, 2010/ 2011. Disponível em: <http://www.acoalfaplp.net>. Publicado em: setembro de 2010 - março de 2011.

Recebido em outubro de 2009./ Aprovado em dezembro de 2009.

Sede da Edição: Faculdade de Educação da Universidade de São Paulo - Av. da Universidade, 308 - Bloco A, sala 111 - São Paulo - SP - Brasil - CEP 05508-040. Grupo de pesquisa: Acolhendo Alunos em situação de exclusão social e escolar: o papel da instituição 